\section{Review Article}

General Laboratory Medicine

\title{
Sustainability in Healthcare: Perspectives and Reflections Regarding Laboratory Medicine
}

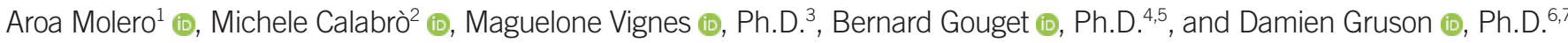 \\ ${ }^{1}$ Health First Europe, Brussels, Belgium; ${ }^{2}$ European Health Management Association Brussels, Belgium; ${ }^{3}$ Metrolab, Université Catholique de Louvain, \\ Brussels, Belgium; ${ }^{4}$ IFCC Committee on Mobile Health and Bioengineering in Laboratory Medicine, Milano, Italy; ${ }^{5}$ Human Healthcare Division COFRAC \\ (Committee Comité Français d'accréditation), Paris, France; ${ }^{6}$ FCC Emerging Technologies Division, Milano, Italy; ${ }^{7}$ Department of Laboratory Medicine, \\ Cliniques Universitaires Saint-Luc and Catholic University of Louvain, Brussels, Belgium
}

Healthcare structures serve to protect and improve public health; however, they can have negative effects on human well-being and the environment. Thus, sustainability is an important target in a rapidly changing healthcare environment. We analyzed the state of the art in research on healthcare and sustainability by exploring literature on different healthcare systems and their relations with the environment. Our review presents conceptual and practical developments regarding sustainability, as well as an overview of their evolution in the healthcare sector over time. We also discuss how sustainability could be applied to reduce the environmental impact of clinical laboratories by ensuring that resources are used efficiently and responsibly. Finally, we describe how laboratory medicine can contribute to a sustainable healthcare system through integration of innovation and emerging technologies while providing high-quality services to patients and caregivers.

Key Words: Healthcare, Sustainability, Environment, Laboratory medicine
Received: January 4, 2020

Revision received: February 21, 2020

Accepted: September 19, 2020

\section{Corresponding author:}

Damien Gruson, Ph.D.

Service de Biochimie Médicale, Cliniques

Universitaires Saint-Luc Tour Claude

Bernard, 54 Avenue Hippocrate, B-1200

Brussels, Belgium

Tel: +32(0)2-7646747

Fax: $+32(0) 2-7646930$

E-mail: damien.gruson@uclouvain.be

\section{(c) (1) (\$)}

C) Korean Society for Laboratory Medicine This is an Open Access article distributed under the terms of the Creative Commons Attribution Non-Commercial License (https://creativecommons.org/licenses/by-nc/4.0) which permits unrestricted non-commercial use, distribution, and reproduction in any medium, provided the original work is properly cited.

\section{INTRODUCTION}

Sustainability is an important point of attention for the public at large, for governments, and for the healthcare system [1-3]. Previously, the term sustainability has been mostly related to environmental degradation [4]. Nowadays, the significance of sustainability has evolved and is related to other aspects, such as the well-being of patients, healthcare employees, and the community. Hence, a sustainable structure should be defined as a one that ensures preservation of resources, is practical from ecological, social, and economical perspectives, and meets the interests of different stakeholders. There is sufficient literature suggesting methods for improving sustainability in healthcare systems; however, there is no consensus on feasible strategies for implementing the proposed sustainability measures in clinical laboratories despite several opportunities [1-3].

In this review article, we present the state of the art in research on sustainability practices in the healthcare sector based on an exploration of the scientific literature and showcase the most suitable practices to support their hastened implementation. We also challenge conventional sustainability practices in the healthcare sector and remind managers of their responsibility not only to follow best practices but also to manage environmental and economic impact for the benefit of the larger community. Furthermore, we discuss the relation between laboratory strategies and sustainability, topics not discussed often enough in the scientific literature. 


\section{DEFINITION AND EVOLUTION OF THE TERM "SUSTAINABILITY"}

The meaning of sustainability is constantly evolving in this rapidly changing world. One of the very first official articulations of sustainable development was made in the Burtland Report, published by the United Nations in 1987, in which sustainable development was defined as "development that meets the needs of the present without compromising the ability of future generations to meet their personal needs" [2, 4]. However, this definition is largely open to interpretation, which has made it difficult to build a consensus on the topic of sustainability. The Swedish scientist Karl-Henrik Robert proposed a more practical definition [4]. According to him, an ideal society would strive to reduce the consumption of mineral and other natural resources.

The definition of sustainable development proposed by the European Union (EU) is broader and more holistic and considers the multiple facets of all sustainability policies, including economical, human, and environmental facets [4].

\section{SUSTAINABILITY IN HEALTHCARE}

Healthcare structures serve to preserve and improve public health; however, their environmental impact can negatively affect wellbeing of humans and other organisms [5]. Therefore, sustainability of hospitals and healthcare structures is also key to promoting human well-being and health. However, the sustainability measures implemented in healthcare structures need to ensure that the quality of service provided by healthcare structures and access to and affordability of healthcare are not compromised, so that both businesses and customers benefit [4, 6, 7]. Another important issue to be tackled regarding sustainability in the healthcare sector is the management of waste disposal and air pollution [8]. Klangsin \& Harding [9] showed how medical waste has become one of the top pollutant sources worldwide and is a major factor affecting disease spread and air, water, and soil quality in and around healthcare structures [9]. Thus, it has become imperative for healthcare organizations to have a multidisciplinary team addressing various aspects of sustainability in healthcare.

Moreover, as public healthcare has a huge impact on national economies and accounts for $23.7 \%$ of employment in the EU [10], sustainability measures in the healthcare sector are also needed to reduce its negative impacts on the national environment and economy [3].

\section{REFLECTIONS ON LABORATORY MEDICINE}

Sustainable thinking has already been introduced in the laboratory community, and multiple means have been proposed, through which clinical laboratories can establish sustainable development goals and reduce their environmental impact (Table 1) [11].

\section{Promoting operational excellence [11]}

Clinical laboratories can rely on new tools, such as artificial intelligence and in-silico modeling, to optimize both clinical and operational processes [12].

\section{Promoting responsible use of natural resources}

A clinical laboratory uses far more energy and water per unit area than a typical office building; therefore, there is a need to adopt good environmental practices in clinical laboratories [11]. Actions to implement these practices include the development of an optimal-resource-management system and an appropriate environmental policy. Data mining and artificial intelligence could contribute to maximizing energy efficiency and measuring and controlling carbon and water footprints; their use for implementing good environmental practices should thus be encouraged [13]. Cloud computing allows laboratories to minimize on-site hosting, while reaping the benefits of limitless data storage and access to continual technology updates and reduced costs. The holding of conferences and events virtually can also help reduce carbon emissions and footprints to a great extent.

Table 1. Targets for sustainable practices in clinical laboratories

Rational test ordering and reduction of test redundancy

Reduction of tubes and materials for collecting body fluids

Policy of reuse

On-site recycling of organic solvents

Reduction of solid waste

Green purchasing

Paper-less policy

Reduction of energy and water consumption

Encouragement of reduction of gasoline consumption by laboratory logistics and staff (encourage and reward use of public transport, carpools, and bicycles)

Usage of energy-efficient and environment-friendly design recommendations for buildings

Use of renewable energy sources, including wind, solar photovoltaics, and solar thermal energy

Increased collaboration for resource sharing (opportunities for cooperation between hospital buildings and laboratory networks) 
Engaging the clinical laboratory workforce as implementors of sustainable practices.

A lack of knowledge and/or awareness regarding sustainability among clinical laboratory employees is currently one of the most commonly described barriers for sustainability in healthcare. National and international scientific societies have a fundamental role to play in reducing this awareness gap by providing educational materials and conducting continuing education sessions.

\section{Promoting a rational test ordering policy}

A revision of the existing laboratory test ordering policy and avoidance of unnecessary laboratory tests would strongly contribute to sustainability [14]. Blumberg, et al. [15] showed that changing how laboratory test requests are presented in electronic health records is associated with changes in the number of laboratory tests ordered. The authors observed that a slight decrease in the convenience of ordering a laboratory test that is not indicated for routine screening (e.g., glutamyl transferase test) led to a dramatic decrease in the number of test orders sent. In addition, the evolution of electronic health records offers new solutions for best-practice alerts. Bejjanki, et al. [16] demonstrated that best-practice alerts significantly reduced repeated tests for serum hemoglobin $A 1 c$, vitamin $B_{12}$, serum erythrocyte sedimentation, serum folate, serum iron, lipid panel, respiratory viral panel, serum thyroid stimulating hormone, and vitamin $\mathrm{D}$, with an estimated overall cost reduction of $\$ 72,543$ over 17 months in the post-intervention period. The management of test ordering to monitor chronic diseases in primary care can also improve overall healthcare quality and reduce cost [17]. The optimization and standardization of blood test ordering for monitoring chronic conditions in primary care was estimated to reduce testing as well as downstream referral costs by $£ 200,000$ for a population of approximately 180,000 patients [17]. However, Bindraban and coworkers showed that well-designed controlled trials using clearly described interventions and relevant clinical outcomes are needed to confirm the efficiency [18].

\section{Participation in disease prevention}

The definition and assessment of the value of laboratory tests and processes are key to sustainability efforts according to new models of care pathways and time-specific services. As healthcare budgets are increasingly restricted, clinical laboratories need to demonstrate their added value in new ways, with a focus on improving clinical outcomes. This should be considered as an opportunity to add value to healthcare by incorporating sustainability measures, rather than solely focusing on driving down the cost per episode of care. Clinical value can also be added by disease prevention, which is often cited as a sustainability measure.

\section{Promoting emerging technologies and innovative models of care}

The actual environmental impact of clinical laboratories needs to be studied further to fill the current knowledge and literature gaps. Clinical laboratories are often among the first workplaces where innovative technologies, including telemedicine, e-health, and mobile health, are applied on a daily basis [13]. Such emerging technologies can also play a role in disease prevention and thus healthcare sustainability. Changing clinical guidelines and standard operating procedures to reflect environmental sustainability saves costs through a reduced need for care [13]. Innovative models of care, such as mobile health solutions, and distributed care, based on better coordination between primary, secondary, and tertiary levels of care, could also greatly contribute to disease prevention.

Table 2. Sets of potential indicators of sustainability

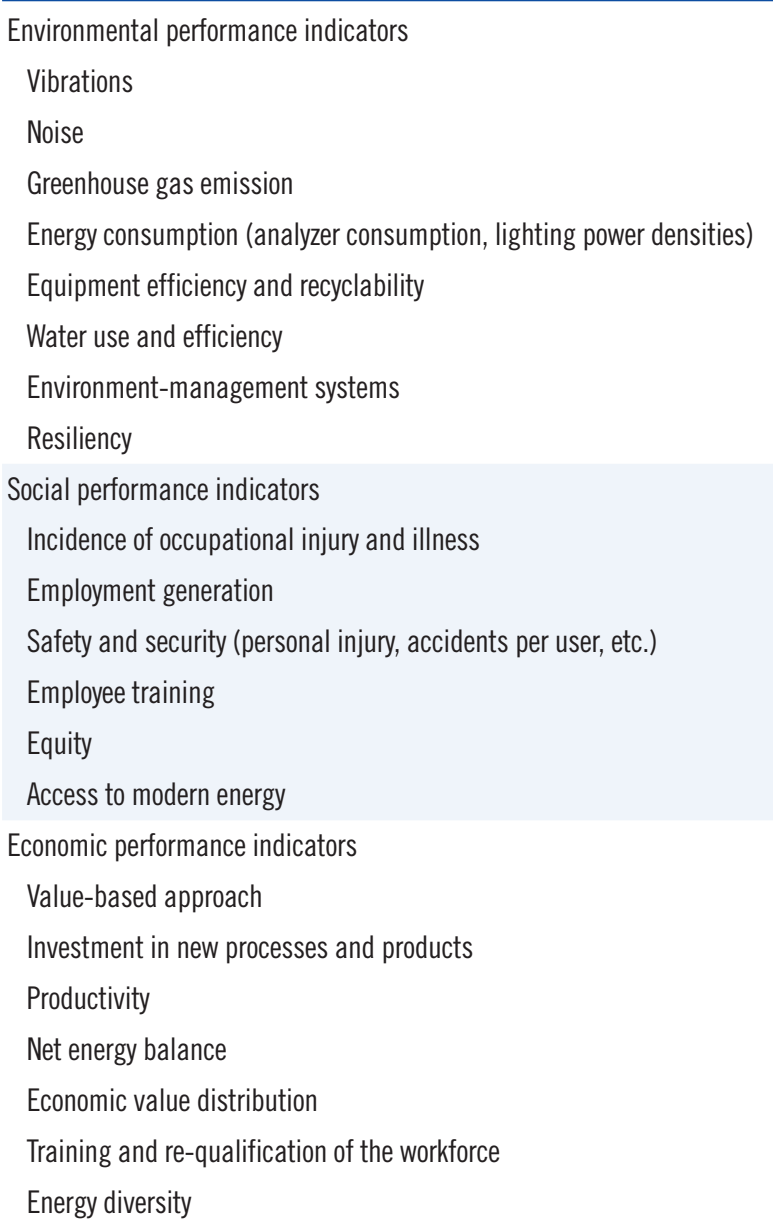


For the assessment of actions to implement better environmental practices in laboratories, it will be important to define and monitor indicators for measuring progress towards sustainability [16]. Table 2 lists examples of such indicators. Data evaluations are needed to determine environmental costs and benefits and build models for estimating the impacts of the above-mentioned actions, and interdisciplinary research is expected to support the development of sustainable integrated care models.

\section{IMPORTANCE OF REDUCING THE ECOLOGICAL IMPACT OF HEALTHCARE}

Most industry analysists will understand that attaining optimal delivery while minimizing environmental risk requires substantial planning. Being environmentally aware and accountable is no longer a bonus or a status symbol; it is something that is increasingly being demanded by our society, making it a key component of rather than an added value to a service [2].

Hospitals, health practitioners, and the laboratory medicine community should lead the shift to carbon neutrality by decreasing their environmental footprint and implementing efficient approaches to address the effects of climate change and pollution without compromising the quality of healthcare [19].

Considering that healthcare accounts for approximately half of the EU government's expenditure [10], sustainable procurement and sale of materials for the healthcare sector is an opportunity for EU government and healthcare users to strategically attain sustainable growth goals [19]. With more than 15,000 hospitals in the EU [20], the European healthcare industry can play a major role in affecting the supply and demand of healthcare products and in leading the shift to safer, more creative, and more viable goods and services.

The major focus of governments and the healthcare sector should be on the six domains of healthcare waste identified by the Institute of Medicine and by Berwick and Hackbarth, which include failure of care delivery, failure of care coordination, overtreatment or low-value care, pricing failure, fraud and abuse, and administrative complexity [21]. Recently, Shrank, et al. [21] estimated that the cost of waste disposal in the US healthcare system ranged from $\$ 760$ billion to $\$ 935$ billion, accounting for approximately $25 \%$ of the total healthcare expenditure; thus, sustainable practices in healthcare waste disposal should also be implemented.

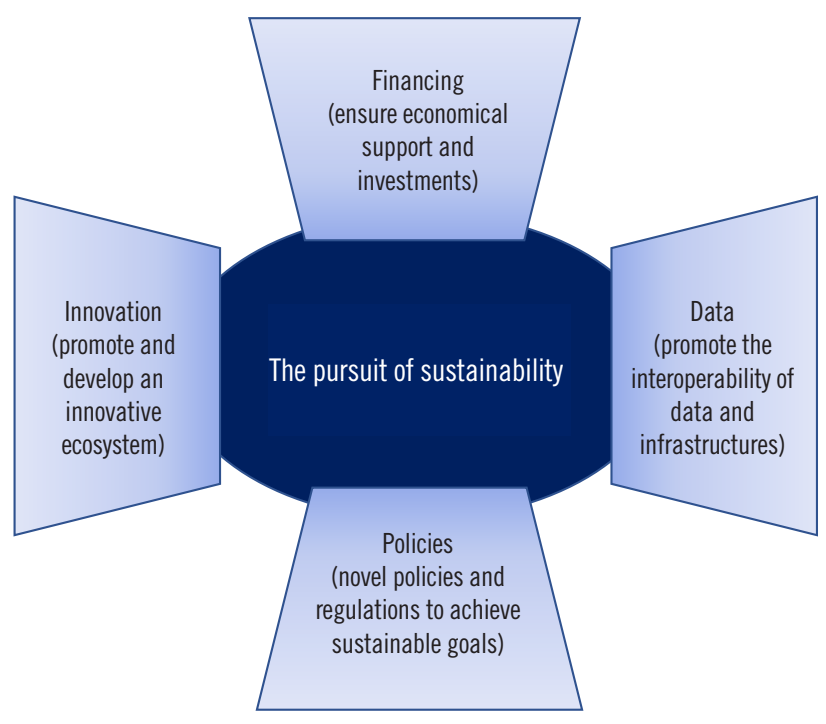

Fig. 1. Pillars of sustainable development in the laboratory medicine environment.

\section{THE PURSUIT OF SUSTAINABILITY}

Several actions are envisioned in the pursuit of sustainability (Fig. 1) [22, 23]:

- Recognition and promotion of the value of sustainable approaches by policymakers.

- Publication of action plans, guidelines, and policy documents regarding sustainable practices.

- Promulgation of novel policies for achieving sustainability goals and implementation of procurement and environment policies related to sustainability.

- Encouragement of laboratory medicine professionals to implement sustainability measures and communicate new insights and outcomes.

- Implementation of a sustainable procurement system that aligns suppliers and contractors in the healthcare system with the sustainability plan.

- Provision of economical support to sustainable initiatives and research and development through indirect fiscal incentives, such as tax credits, or direct grants and loans.

- Engagement of investors to build sustainable financial markets.

- Catalyzation of innovation, emerging technologies, and experimentation for addressing social, environmental, and economic challenges.

- Facilitation of transparent, standardized, and interoperable data sharing.

- Ensuring of funding of data infrastructure. 


\section{EU MEASURES TO PROMOTE HEALTHCARE SUSTAINABILITY}

The European Green Deal (EGD) Investment Plan, also known as the Sustainable Europe Investment Plan, will mobilize at least $€ 1$ trillion for sustainable investments over the next decade to achieve its objectives, which aim at making Europe the world's first climate-neutral continent by 2050 [24]. To achieve this goal, renewable power sources should become the main sources of energy in the EU. However, the effectiveness of the EGD depends on the involvement of all EU stakeholders. The European Commission has already taken some initiatives focusing on hospitals and healthcare stakeholders, such as "Towards Zero Carbon Hospitals with Renewable Energy Systems" [25], which aim to reduce $\mathrm{CO}_{2}$ emissions from the 15,000 hospitals in Europe by providing them suitable tools to achieve greater sustainability. Their relatively high energy requirements make hospitals an ideal subject for exploring non-technical barriers to energy efficiency measures and renewable energy systems. However, in contrast to new hospitals, which can be designed to be energy-efficient, existing EU hospitals will need to focus on reducing energy consumption and exploiting renewable energy sources to achieve the long-term $\mathrm{CO}_{2}$-reduction targets set by the European Commission. Further, a high-quality "Guide for European Hospitals on Renewable Energy" targeting decision-makers and based on good practices and lessons learned from regional hospitals has been developed and widely distributed [26]. This initiative incentivizes the pursuit of sustainability in healthcare structures and promotion of environment-friendly attitudes among all healthcare stakeholders, which can benefit the whole system.

\section{CONCLUSIONS}

The relation between sustainability and healthcare is a current research topic and needs to be applied more deeply to laboratory medicine. We hope to increase awareness about sustainability in healthcare from a holistic point of view and grow the body of literature on this important topic. Maintaining a sustainable healthcare system while providing high-quality, effective, and safe healthcare is a major economic and social challenge for healthcare services and consumers. The cost-saving potential of a more efficient use of energy and other resources in healthcare systems is clear; yet, there is a long way to go for environment-friendly hospitals, healthcare structures, and clinical laboratories to become the norm. Good collaboration among the EU healthcare systems and a common vision for future actions would help achieve such goals. Due consideration should be given to the environment and healthcare in EU policies, and any strategy for achieving a sustainable future for Europe will have to consider their interconnectedness. In line with its values, the EU should seek to promote the well-being, security, and interests of European citizens, and sustainability will have to continuously inspire the European Commission's political decisionmaking and guide the development of the post-EU2020 growth strategy.

The global environmental crisis will only worsen unless all societal implementors are held accountable for the true cost and risk of polluting nature and its consequences to the public and the environment. Too much responsibility for reducing environmental footprints is currently focused on citizens and waste management, and efforts made by individuals will remain insufficient unless action is taken across the entire value chain.. Acting too late in reducing our environmental footprint will pose major public health and environmental risks. Solutions, ranging from waste reduction to collection and recycling, to avoid the impending environmental crisis can be implemented only if all stakeholders are held accountable for their actions and the impact of these on the environment.

\section{AUTHOR CONTRIBUTIONS}

All authors designed, prepared, and revised the manuscript.

\section{CONFLICT OF INTEREST}

None.

\section{RESEARCH FUNDING}

This research was supported by the European Regional Development Fund (ERDF), the Région Bruxelles Capitale, and the project "Laboratoire de Proximité" (ERDF F11-02).

\section{ORCID}

Aroa Molero

Michele Calabrò

Maguelone Vignes

Bernard Gouget

Damien Gruson https://orcid.org/0000-0002-1251-5859 https://orcid.org/0000-0002-6993-0527 https://orcid.org/0000-0002-4775-864X https://orcid.org/0000-0002-8010-1404 https://orcid.org/0000-0001-5987-4376 


\section{REFERENCES}

1. Mosca I, van der Wees PJ, Mot ES, Wammes JJG, Jeurissen PPT. Sustainability of long-term care: puzzling tasks ahead for policy-makers. Int J Health Policy Manag 2017;6:195-205.

2. Biason KM and Dahl P. Strategic steps to sustainability in healthcare Sustainable Operations. https://healthcarefacilitiestoday.com/posts/Strategic-steps-to-sustainability-in-healthcare--13629 (Updated on Oct 2016).

3. World Health Organization Regional Office for Europe. Environmentally sustainable health systems: a strategic document 2017. http://www. euro.who.int/en/health-topics/Health-systems/public-health-services/ publications/2017/environmentally-sustainable-health-systems-a-strategic-document-2017.

4. Marimuthu $\mathrm{M}$ and Paulose $\mathrm{H}$. Emergence of sustainability-based approaches in healthcare: expanding research and practice. Procedia Soc Behav Sci 2016;224:554-61.

5. Buffoli M, Capolongo S, Bottero M, Cavagliato E, Speranza S, Volpatti L. Sustainable healthcare: how to assess and improve healthcare structures' sustainability. Ann Ig 2013;25:411-8.

6. Chandra H, Rinkoo AV, Verma JK, Verma S, Kapoor R, Sharma RK. Supply chain management with cost-containment and financial-sustainability in a tertiary care hospital. J Health Hum Serv Admin 2013;36:3-23.

7. Price R, Sergelen O, Unursaikhan C. Improving surgical care in Mongolia: a model for sustainable development. World J Surg 2013;37:1492-9.

8. Berwick DM and Hackbarth AD. Eliminating waste in US health care. JAMA 2012;307:1513-6.

9. Klangsin P and Harding AK. Medical waste treatment and disposal methods used by hospitals in Oregon, Washington, and Idaho. J Air Waste Manag Assoc 1998;48:516-26.

10. European Commission, Eurostat. Renewable energy statistics. https:// ec.europa.eu/eurostat/statistics-explained/index.php?title=Renewable energy_statistics (Updated on Jan 2020).

11. Lopez JB, Jackson D, Gammie A, Badrick T. Reducing the environmental impact of clinical laboratories. Clin Biochem 2017;38:3-11.

12. Gruson D, Helleputte T, Rousseau P, Gruson D. Data science, artificial intelligence, and machine learning: opportunities for laboratory medicine and the value of positive regulation. Clin Biochem 2019;69:1-7.

13. Greaves RF, Bernardini S, Ferrari M, Fortina P, Gouget B, Gruson D, et al. Key questions about the future of laboratory medicine in the next decade of the 21st century: a report from the IFCC-Emerging Technologies Division. Clin Chim Acta 2019;495:570-89.

14. Verna R, Velazquez AB, Laposata M. Reducing diagnostic errors world- wide through diagnostic management teams. Ann Lab Med 2019;39: 121-4.

15. Blumberg G, Kitai E, Vinker S, Golan-Cohen A. Changing electronic formats is associated with changes in number of laboratory tests ordered. Am J Manag Care 2019;25:e179-81.

16. Bejjanki H, Mramba LK, Beal SG, Radhakrishnan N, Bishnoi R, Shah C, et al. The role of a best practice alert in the electronic medical record in reducing repetitive lab tests. Clinicoecon Outcomes Res 2018;10:611-8.

17. Bindraban RS, Ten Berg MJ, Naaktgeboren CA, Kramer MHH, Van Solinge WW, Nanayakkara PWB. Reducing test utilization in hospital settings: a narrative review. Ann Lab Med 2018;38:402-12.

18. Whiting D, Croker R, Watson J, Brogan A, Walker AJ, Lewis T. Optimising laboratory monitoring of chronic conditions in primary care: a quality improvement framework. BMJ Open Qual 2019;8:e000349.

19. Directorate-General for Environment (European Commission), Intrasoft International, University of the West of England (UWE), Science Communication Unit, Indicators for sustainable cities. https://publications. europa.eu/en/publication-detail/-/publication/cbaa6e59-437c-11e8-a9f401aa75ed71a1 (Updated on March 2018).

20. Health Care Without Harm, EUKI Anaesthetic Gases Project. Fostering low carbon healthcare in Europe. https://noharm-europe.org/issues/europe/fostering-low-carbon-healthcare-europe-euki-anaesthetic-gasesproject (Updated on 2018).

21. Chevalier F, Lévitan J, Garel P. Hospitals in the 27 Member States of the European Union. 2009, pp. 55-99. http://www.hope.be/wp-content/uploads/2015/11/79_2009_OTHER_Hospitals-in-27-Member-States-ofthe-European-Union-eng.pdf

22. Shrank WH, Rogstad TL, Parekh N. Waste in the US health care system: estimated costs and potential for savings. JAMA 2019;322:1501-9.

23. OECD and the Sustainable Development Goals: delivering on universal goals and targets. OECD. http://www.oecd.org/dac/sustainable-development-goals.htm (Updated on 2019).

24. European Commission, Directorate General for Environment. Sustainable development 2020. https://ec.europa.eu/environment/sustainabledevelopment/

25. European Commission. The European Green Deal Investment Plan and Just Transition Mechanism explained, 2020. https://ec.europa.eu/commission/presscorner/detail/en/qanda_20_24 (Updated on Jan 2020).

26. European Commission. Energy intelligent, energy Europe; towards zero carbon hospitals with renewable energy systems, 2020. https://ec.europa.eu/energy/intelligent/projects/en/projects/res-hospitals (Updated on Sep 2020). 